\title{
Review of Research Progress on Perceived Organizational Support and Organizational Identity
}

\author{
Hengwei Luo \\ Jinan University, Guangzhou, China \\ Email: heylhw@163.com
}

How to cite this paper: Luo, H.W. (2020) Review of Research Progress on Perceived Organizational Support and Organizational Identity. Open Journal of Business and Management, 8, 809-819.

https://doi.org/10.4236/ojbm.2020.82050

Received: March 2, 2020

Accepted: March 20, 2020

Published: March 23, 2020

Copyright $\odot 2020$ by author(s) and Scientific Research Publishing Inc. This work is licensed under the Creative Commons Attribution International License (CC BY 4.0).

http://creativecommons.org/licenses/by/4.0/

\section{(c) (i) Open Access}

\begin{abstract}
Both organizational support and organizational identity are concepts derived from social exchange theory and social identity theory. And both of them are closely related to organizational performance. However, there is still controversy over the construction, measurement, and relationship between the two. Therefore, we aim to clarify the relationship between perceived organizational support and organizational identity and to point the way for future research. This paper reviews the previous literature on the dimensions and measurement methods of organizational support and organizational identity. It mainly discusses the research on combining two constructs at home and abroad in recent years. Finally, based on the review of the two constructs, this article enlightens further discussion on future development trends.
\end{abstract}

\section{Keywords}

Perceived Organizational Support, Organizational Identity, Organization Performance

\section{Introduction}

The globalization of production and sales means more intense competition. In order to gain an advantage in this competition and achieve corporate strategic goals, human resource management plays a vital role in helping companies achieve these strategic goals. The Employee-Organization Relationship (EOR) is an important part of human resource management. In today's rapidly changing market environment, how to understand EOR has become a new topic facing organizational managers.

Perceived organizational support (POS) describes an employee's perception of 
the importance the organization places on his contribution and the existence of him. Organizational identification (OI) refers to the consistency of an individual with an organization or the perception that an individual is subordinate to an employee. They both are important constructs subordinate to EOR and many existing studies have shown that these two constructs are highly related to employee job performance. Based on theories of social exchange, self-attribution, and self-improvement, Eisenberger et al. [1] used a meta-analysis of the theory of organizational support using the results of 558 studies. The study found that organizational support perceived antecedent variables (including leadership, employee-organizational context, human resource practices, and working conditions) and outcome variables (employees' positioning of the organization and work, job performance, and presence). Riketta's [2] meta-analysis of organizational identity for 96 studies shows that organizational identity is related to a range of work attitudes, behaviors, and situational variables, affirming the impact of organizational identity on employee performance. Domestic scholars Bao and $\mathrm{Xu}$ [3] compiled previous empirical research on organizational identity and concluded that the impact of organizational identity on the organization is mainly reflected in five aspects: cooperation intention, satisfaction, organizational self-esteem, organizational citizenship behavior, and intention to leave.

In summary, this study attempts to answer the following questions through literature review

1) What are the common dimensions and measurement methods for perceived organizational support and organizational identity?

2) What is the connection between organizational support and organizational identity? Mediation or Moderator?

3) What are the shortcomings of existing research on perceived organizational support and organizational identity and what are the future development directions?

\section{Dimensions and Measurement of POS and OI}

\subsection{Dimension and Measurement of Perceived Organizational Support}

Organizational support is a concept based on the theory of organizational support theory and social exchange theory. Organization Support Theory (OST) [4] [5] proposes that employees will form a general perception about the extent to which organizations value what they do contributions and concerns about their presence in the organization. That is, perceived organizational support (POS). The degree of organizational support depends on the employee's attribution to the organization's intentions. Social exchange theory believes that a social exchange process begins with perceived organizational support (POS), that is, employees feel obliged to help the organization achieve its goals and expect that this effort for the growth of the organization's interests can be exchanged for more returns, thereby forming a kind of reciprocity norm. 
At present, the division of perceived organizational support dimensions commonly used in foreign countries is the one-dimensional feature of organizational support proposed by Eisenberger et al. [4], and developed a measurement tool to evaluate perceived organizational support of employees including a 36-item declarative scale, that is, survey of perceived organizational support. They believe that POS is related to social support and work stress feelings, emphasizing that employees can obtain emotional support from the organization when external pressure increases. Subsequent studies on the reliability and validity of organizational support have also confirmed the single dimensional characteristics of perceived organizational support. Shore [6] and Hutchison [7] further confirmed the one-dimensional feature of perceived organizational support in the study of structural validity of perceived organizational support.

However, many scholars believe that organizational support is a type of social support, and social support has support from different objects such as work, family and friends. Therefore, organization support is considered as a multi-dimensional concept. McMillan [8] divides organization support into emotional support and instrumental support, that is, the former refers to employees' perception of affection, acceptance, and care, and the latter refers to training, equipment and information from the organization. Ladd and Henry [9] divided organizational support into support from colleagues and support from superiors from the perspective of organizational support sources.

Domestic scholars Ling, Yang, and Fang et al. [10] explored the multi-dimensional psychological structure of organizational support in the context of Chinese culture, and divided organizational support into work support, recognition value, and interest concern. Shao and Fan et al. [11] combined the sentimental and instrumental content perspectives of organizational support, as well as the support sources of their superiors and colleagues, to construct the four-dimensional conceptual model including perceptual emotional superior support, perceived emotional peer support, and perceived instrumental superior support and perceived instrumental colleagues support. Besides, they developed a perceived organizational support scale that fits the Chinese cultural background. In this scale, the measurement of perceived organizational support consists of 18 items in 4 dimensions, and the support provided by the organization consists of 13 items in 3 dimensions. And the results of the exploratory factor analysis and confirmatory factor analysis test on the scale have good reliability and validity.

\subsection{Dimensions and Measurements of Organization Identity}

Since Ashforth and Meal [12] introduced the theory of social identity to the field of organizational research, they defined organizational identity as the consistency between individuals and organizations or the perception that individuals are subordinate to organizations. They believed that individuals had essential needs to connect the concept of self with others and a need that belongs to a larger organization from the perspective of individual motivation. They also emphasize 
that organizational identity is a one-dimensional cognitive structure. However, more scholars believe that organizational identity is a multi-dimensional concept. In addition to the cognitive dimension, Sluss et al. [13] divide organizational identity into two dimensions: emotion and behavior. The former refers to the emotional dependence of organizational members on the organization. The latter refers to the behavior of organization members corresponding to their organizational identity. Wei et al. [14] summarized the definition of organizational identity based on domestic and foreign research as "an individual's self-construction that originates from organizational membership. It is the result of an individual's recognition and internalization of organizational values. It is also an individual's emotional refuge in aspects such as pride and loyalty." In terms of the form of identification, Elsbach et al. [15] proposed a four-dimensional model of organizational identification based on the process of interaction between organizational members and organizations, including identification, dis-identification, ambivalent, and neutral identification. The empirical research by Kreiner and Ashforth [16] ranks the above four concepts according to their level of identification as identification, ambivalent, neutral identification, and dis-identification. The above division of organizational identification dimensions is mostly proposed by foreign scholars based on foreign backgrounds. Sun et al. [17] used qualitative research methods to explore the dimensions of organizational identification in the Chinese context, and finally proposed 9 dimensions, including sense of belonging, identity perception, member similarity, consistency between individuals and organizations, organizational attractiveness, organizational participation, gratitude and allegiance, interpersonal relationships, and contractual relationships. The first six dimensions are similar to the divisions of Western studies, and the last three dimensions are unique to Chinese culture.

In terms of organizational identity measurement, Cheney [18] developed measurement tools including membership, loyalty, and similarity, and developed the most widely used organization identification questionnaire, OIQ). The scale developed by Mael and Tetrick [19] is based on their belief that organizational identity is a special form of social identity and contains only cognitive dimensions, which is a Likert scale with six items. Based on the theory of social identity and self-classification. Dick [20] believes that organizational identity has four dimensions: cognitive, affective, evaluation, and behavior. The scale he developed includes 7 items which had been proved high reliability and validity by the empirical research. However, Riketta's [2] comprehensive meta-analysis of 96 studies on organizational identification shows that the Male scale is more favored by researchers in explaining causal studies than OIQ and is more commonly used in work behavior research.

\section{The Relationship between Perceived Organizational Support and Organizational Identity}

In recent years, the number of researches on organizational support and organi- 
zational identity is still on the rise, both of which are related to the cognitive level of the organization and individual employees. Although for the two alone, domestic and foreign studies have matured for their antecedent and outcome variables, few studies have explored the relationship between the interaction of these variables. Does perceived organizational support play a mediating or moderating role in the process of affecting organizational identity? What is the mechanism of perceived organizational support and organizational identity, and how does organizational support affect individual behavior when it crosses with organizational identity? These problems are the recent concerns of scholars.

Cheung et al. [21] established a model to study the relationship between organizational fairness and organizational identity and the mediating role of perceived organizational support and the results of a study of 159 employees in the service industry show that perceived organizational support played a full mediating role on the relationship between interpersonal equity and information equity and organizational identity. Based on the framework of social exchange and social identification, Jeewon et al. [22] tested the mediating role of perceived organizational support and organizational identity between procedural fairness and organizational citizenship behavior on two cross-cultural samples of South Korea and the United States and the result only support the intermediary role of organizational identification, and the role of perceived organizational support is excluded.

David et al. [23] studied the relationship between relationship exchange and personal identity within the organization, and found that the sense of organizational support acts as an intermediary role between the leader-member exchange and organizational identity through cross-level data from 364 superior-subordinate two parties, his conclusion expanded the theory of social exchange and social identity. Zagenczyk et al. [24] explored how employees integrate organizational identity into their own identity and the results showed that perceived organizational support completely mediates relational psychological contract breaches (commitments related to training, personal development, and job security) and organizational identity rather than transactions psychological contract violations (commitments related to salary and working hours) and organizational identity. Perceived organizational support partly mediates the breach of relational psychological contract and organization dis-identity rather than the breach of transactional psychological contract and organization dis-identity. Caesens et al. [25] considered both social exchange and social identity perspectives, and verified that obligation perception and organizational identity play a part of the mediating role between perceived organizational support and emotional organizational commitment. Lam et al. [26] used three-wave data collection methods to collect information on organizational support, organizational identity, and out-of-role behaviors (behaviors that meet organizational needs rather than personal interests) from 363 nurses in China Information and the empirical results show that organizational identity plays an intermediary role between per- 
ceived organizational support and employees' external behaviors, and collectivism plays a moderating role in the process.

In recent years, mainstream research has begun to conceptualize the relationship between perceived organizational support and organizational identity from the process of social identity and social exchange. Demir et al. [27] based on survey data of 169 preschool education teachers in Turkey to study how organizational identity acts as an intermediary for perceived organizational support and organizational citizenship behavior. The results showed that organizational justice and perceived organizational support together explain the $70 \%$ variance in teacher organizational identity. Organizational identity explains the $79 \%$ variance in teacher organizational citizenship behavior. Chen [28] used post-80s employees in the financial services industry as his research object in his master's thesis, studying the relationship between perceived organizational support, organizational identity, and work involvement (employees in the organization can control themselves and combine self with job roles). The results show that organizational identity plays a part of the mediating role between perceived organizational support and work engagement. Li [29] explored four variables: organizational support, organizational identity, speech behavior and leadership member exchange. The empirical results show that organizational identity plays a part of the mediating role between organizational support and speech behavior, while the leadership member exchange is positively moderated the relationship between perceived organizational support and organizational identity. $\mathrm{Xu}$ [30] used a multi-sample structural equation modeling method to verify the partial mediated role of insider identity awareness (PIS) and organization-based self-esteem between perceived organizational support and organizational identity by analyzing 452 valid data obtained from employee questionnaire surveys of two Chinese companies.

It can be seen that the relationship between organizational identity and organizational support is very similar and even easily confused. Existing research have studied the antecedent variables that affect individual behaviors within organizations from different perspectives. It can be concluded that POS and OI often interchange the roles of intermediaries, and the role of moderator is less mentioned. In addition, their impact on the behavior of individuals in the organization is basically simultaneous, it is difficult to say that there is a clear sequence.

\section{Management Implications}

Organizational support and organizational identity, as a kind of psychological relationship or emotional bond between individuals and organizations, play a very important role in the process of organizational growth and development. Thus, research on them has the following implications for managers in organizations.

In terms of human resource management practices, in order to promote employees' recognition of the organization and further stimulate the enthusiasm of 
the employees, the organization should strengthen cooperation with scientific research institutions and improve the theoretical level of organizational identity management on the one hand; on the other hand, it should be based on Chinese cultural background, strengthen the management of the identity of individual organizations within the organization.

In terms of employee relationship management, studies by Zagenczyk et al. [24] show that organizations should pay attention to the erosion of positive relationships between employees (organizational identity) and the breeding of negative relationships between employees (organizational dis-identity). Most research on organizational identity shows that managers should not only focus on the impact of external factors (such as organizational reputation and fame) on employees, but also internal factors (such as appropriate rewards and provide required resources) that affect organizational support The direct factor of feeling. High-quality leadership-membership relationships can also effectively maintain employee perceived organizational support and organizational identity and help employees improve work performance, and ultimately achieve the goal of improving organizational performance.

In terms of organizational citizenship, it can be seen from the principle of reciprocity that employees who are perceived to have higher support and higher identification will tend to act in accordance with the interests of the organization, and they will be more willing to invest in the organization to prove that the organization's investment in itself is worth it. In the process of practical management, in order to establish employees' recognition of organizational goals and values, companies should invest a lot of time and funds for employee training. In this interaction process, it is expected that employees' satisfaction can be increased and their due diligence promoted, even doing extra things which are not part of duty but are benefit to the development of the organization.

\section{Further Research}

There is no unified definition and dimensional division of the concepts of organizational support and organizational identity at home and abroad. The mainstream view today is that they all have multiple characteristics. In the future, researchers can examine the impact of perceived organizational support on organizational identity and organizational citizenship behavior from various dimensions or levels of organization from a more subdivided perspective.

There is still a lot of research potential on the combination of organizational identity and organizational support, especially in terms of its relationship with employees or organizational behavior. As for the internal mechanism of action between the two constructs, Xu et al. [30] used a cross-cutting study and both are based on Chinese background. The research by Farh, Hackett, and Liang [31] shows that individuals will be affected by cultural values, future research may consider further verification from longitudinal research and cross-cultural background sample selection. 
Although organizational identity and perceived organizational support originated from social identity theory and social exchange theory, the continuous deepening of the research has been significantly affected by other theories, such as social network theory, social cognitive theory, etc. Wan [32] believes that the introduction of these theoretical perspectives has opened up horizons for the study of organizational identity, both theoretically and empirically. For example, the relational identification proposed by Sluss and Ashforth [13] is based on the theory of social networks, and believes that the relationship between members within an organization is embedded in the organization, so the relational identification is not just juxtaposed with organizational identification at the level, it is a concept that even more embedded in the network of organizational life.

In terms of localization research, Guo [33] compiled foreign literature on organizational identification and found that foreign research has deepened and refined organizational identification: starting from organizational identification, extending to team identification, relationship identification, and moral identification. Overall, the research has not kept up with the international pace. From the perspective of the subcategories of organization identification, specific research on relationship identification and moral identification has not yet fully developed, and organizational identification, especially team identification, is still in its infancy. The existing literature on perceived organizational support and organizational identity are mostly based on foreign contexts. The qualitative research by Sun [17] explores the classification of organizational identity in the Chinese context, and points out three dimensions unique to the Chinese context: gratitude and allegiance, interpersonal relationships, contractual relationships. But he compared the discussions of foreign scholars before 2005. Sluss et al. [34] have proposed relationship identification as part of multiple organizational identification. Therefore, in the study of the sense of organizational support and organizational identity in the Chinese context, we can further consider the division of dimensions under cultural backgrounds and context differences. It is also worth exploring whether relationship identification is measured as a separate dimension or one of the dimensions in organizational identification problem.

\section{Conclusion}

From the review of the origin of organizational support and organizational identity to the latest research on both in recent years, this study further validates the important role that perceived organizational support and organizational identity play in enterprises and sorts out the gaps in current research. In addition, we explore the relationship between POS and OI, and find out how they ultimately affect the personal behavior of employees and then affect corporate performance. All in all, this research has both theoretical and practical value.

\section{Conflicts of Interest}

The author declares no conflicts of interest regarding the publication of this paper. 


\section{References}

[1] Kurtessis, J.N., Eisenberger, R., Ford, M.T., et al. (2017) Perceived Organizational Support: A Meta-Analytic Evaluation of Organizational Support Theory. Journal of Management, 43, 1854-1884. https://doi.org/10.1177/0149206315575554

[2] Riketta, M. (2005) Organizational Identification: A Meta-Analysis. Journal of Vocational Behavior, 66, 358-384. https://doi.org/10.1016/j.jvb.2004.05.005

[3] Bao, G.M. and Xu, B.X. (2006) A Review of Research on Organizational Identity Theory. Foreign Economy and Management, No. 1, 39-45.

[4] Eisenberger, R., Huntington, R., Hutchison, S., et al. (1986) Perceived Organizational Support. Journal of Applied Psychology, 71, 500. https://doi.org/10.1037/0021-9010.71.3.500

[5] Eisenberger, R. and Stinglhamber, F. (2011) Perceived Organizational Support: Fostering Enthusiastic and Productive Employees. American Psychological Association, Washington DC. https://doi.org/10.1037/12318-000

[6] Shore, L.M. and Tetrick, L.E. (1991) A Construct Validity Study of the Survey of Perceived Organizational Support. Journal of Applied Psychology, 76, 637. https://doi.org/10.1037/0021-9010.76.5.637

[7] Hutchison, S. (1997) Perceived Organizational Support: Further Evidence of Construct Validity. Educational and Psychological Measurement, 57, 1025-1034. https://doi.org/10.1177/0013164497057006011

[8] McMillan, R. (1997) Customer Satisfaction and Organizational Support for Service Providers. University of Florida, Gainesville.

[9] Ladd, D. and Henry, R.A. (2000) Helping Coworkers and Helping the Organization: The Role of Support Perceptions, Exchange Ideology, and Conscientiousness. Journal of Applied Social Psychology, 30, 2028-2049.

https://doi.org/10.1111/j.1559-1816.2000.tb02422.x

[10] Ling, W.Z., Yang, H.J. and Fang, L.L. (2006) Organizational Support of Enterprise Employees. Acta Psychologica Sinica, No. 2, 281-287.

[11] Shao, F. and Fan, Y. (2013) Analysis of Organizational Support Dimensions and Scale Verification from a Composite Perspective. Science of Science and Technology Management, No. 11, 159-170.

[12] Ashforth, B.E., Harrison, S.H. and Corley, K.G. (2008) Identification in Organizations: An Examination of Four Fundamental Questions. Journal of Management, 34, 325-374. https://doi.org/10.1177/0149206308316059

[13] Sluss, D.M. and Ashforth, B.E. (2008) How Relational and Organizational Identification Converge: Processes and Conditions. Organization Science, 19, 807-823. https://doi.org/10.1287/orsc.1070.0349

[14] Wei, J., Chen, Z.Y. and Zhang, M. (2007) The Basic Theory, Measurement and Related Variables of Organizational Identity. Advances in Psychological Science, No. 6, 948-955.

[15] Elsbach, K.D. and Bhattacharya, C.B. (2001) Defining Who You Are by What You're Not: Organizational Disidentification and the National Rifle Association. Organization Science, 12, 393-413. https://doi.org/10.1287/orsc.12.4.393.10638

[16] Kreiner, G.E. and Ashforth, B.E. (2004) Evidence toward an Expanded Model of Organizational Identification. Journal of Organizational Behavior. The International Journal of Industrial, Occupational and Organizational Psychology and Behavior, 25, 1-27. https://doi.org/10.1002/job.234 
[17] Sun, J.M. and Jiang, K.F. (2009) The Structure of Organizational Identity in China: An Exploratory Study. Sociological Research, 1, 184-246.

[18] Cheney, G. and Tompkins, P.K. (1987) Coming to Terms with Organizational Identification and Commitment. Communication Studies, 38, 1-15. https://doi.org/10.1080/10510978709368225

[19] Mael, F.A. and Tetrick, L.E. (1992) Identifying Organizational Identification. Educational and Psychological Measurement, 52, 813-824. https://doi.org/10.1177/0013164492052004002

[20] Van Dick, R., Wagner, U., Stellmacher, J., et al. (2004) The Utility of a Broader Conceptualization of Organizational Identification: Which Aspects Really Matter? Journal of Occupational and Organizational Psychology, 77, 171-191. https://doi.org/10.1348/096317904774202135

[21] Cheung, M.F.Y. and Law, M.C.C. (2008) Relationships of Organizational Justice and Organizational Identification: The Mediating Effects of Perceived Organizational Support in Hong Kong. Asia Pacific Business Review, 14, 213-231. https://doi.org/10.1080/13602380701430879

[22] Cho, J. and Treadway, D.C. (2011) Organizational Identification and Perceived Organizational Support as Mediators of the Procedural Justice-Citizenship Behaviour Relationship: A Cross-Cultural Constructive Replication. European Journal of Work and Organizational Psychology, 20, 631-653. https://doi.org/10.1080/1359432X.2010.487363

[23] Oliver, D., Statler, M. and Roos, J. (2010) A Meta-Ethical Perspective on Organizational Identity. Journal of Business Ethics, 94, 427-440. https://doi.org/10.1007/s10551-009-0274-y

[24] Zagenczyk, T.J., Gibney, R., Few, W.T., et al. (2011) Psychological Contracts and Organizational Identification: The Mediating Effect of Perceived Organizational Support. Journal of Labor Research, 32, 254-281. https://doi.org/10.1007/s12122-011-9111-Z

[25] Caesens, G., Marique, G. and Stinglhamber, F. (2014) The Relationship between Perceived Organizational Support and Affective Commitment More than Reciprocity, It Is Also a Question of Organizational Identification. Journal of Personnel Psychology, 13, 167-173. https://doi.org/10.1027/1866-5888/a000112

[26] Lam, L.W., Liu, Y. and Loi, R. (2016) Looking Intra-Organizationally for Identity Cues: Whether Perceived Organizational Support Shapes Employees' Organizational Identification. Human Relations, 69, 345-367. https://doi.org/10.1177/0018726715584689

[27] Demir, K. (2015) The Effect of Organizational Justice and Perceived Organizational Support on Organizational Citizenship Behaviors: The Mediating Role of Organizational Identification. Eurasian Journal of Educational Research, No. 60, 131-148. https://doi.org/10.14689/ejer.2015.60.8

[28] Chen, T. (2015) Research on the Relationship between Organizational Support, Organizational Identity and Job Involvement. Jiangxi University of Finance and Economics, Nanchang.

[29] Li, Y. (2016) A Study on the Relationship between Organizational Support, Organizational Identification and Employees' Suggestion Behavior. Capital University of Economics and Business, Beijing.

[30] Xu, Y., Zhao, L., Wei, L.H., et al. (2017) The Effect of Organizational Support on Organizational Identity: The Mediating Role of Insider Identity Perception and Self-Esteem. Psychological Exploration, No. 3, 275-282. 
[31] Farh, J.L., Hackett, R.D. and Liang, J. (2007) Individual-Level Cultural Values as Moderators of Perceived Organizational Support-Employee Outcome Relationships in China: Comparing the Effects of Power Distance and Traditionality. Academy of Management Journal, 50, 715-729. https://doi.org/10.5465/amj.2007.25530866

[32] Wan, H.Y. (2013) New Advances in Organizational Identity Research: Basic Concepts and Their Formation and Integration Mechanisms. Studies in Psychology and Behavior, No. 3, 425-432.

[33] Guo, S.H. (2016) Identity in Organizations: A Review of Foreign Literatures. Contemporary Economic Management, No. 8, 73-79.

[34] Sluss, D.M., Klimchak, M. and Holmes, J.J. (2008) Perceived Organizational Support as a Mediator between Relational Exchange and Organizational Identification. Journal of Vocational Behavior, 73, 457-464.

https://doi.org/10.1016/j.jvb.2008.09.001 